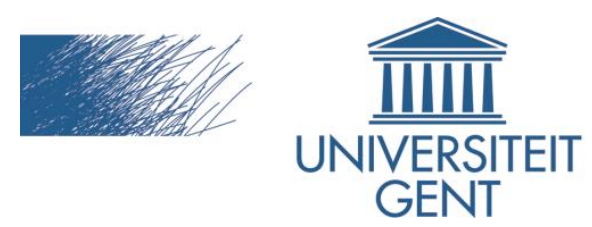

biblio.ugent.be

The UGent Institutional Repository is the electronic archiving and dissemination platform for all UGent research publications. Ghent University has implemented a mandate stipulating that all academic publications of UGent researchers should be deposited and archived in this repository. Except for items where current copyright restrictions apply, these papers are available in Open Access.

This item is the archived peer-reviewed author-version of:

From Milgram to Zimbardo: the double birth of postwar psychology/psychologization Jan De Vos

In: History of the Human Sciences, Volume 23, Number 5

http://hhs.sagepub.com/content/23/5/156.full.pdf+html

To refer to or to cite this work, please use the citation to the published version:

De Vos, J. (2010). From Milgram to Zimbardo: the double birth of postwar psychology/psychologization. History of the Human Sciences, 23(5) 156-175. doi $10.1177 / 0952695110384774$ 


\title{
From Milgram to Zimbardo: the double birth of postwar psy- chology/psychologization
}

\begin{abstract}
Milgram's series of obedience experiments and Zimbardo's Stanford Prison Experiment are probably the two best-known psychological studies. As such, they can be understood as central to the broad process of psychologization in the postwar era. This article will consider the extent to which this process of psychologization can be understood as a simple overflow from the discipline of psychology to wider society or whether, in fact, this process is actually inextricably connected to the science of psychology as such. In so doing, the article will argue that Milgram's and Zimbardo's studies are best usefully understood as twin experiments. Milgram's paradigm of a psychology which explicitly draws its subject into the frame of its own discourse can be said to be the pre-condition of Zimbardo's claim that his experiment offers a window onto the crucible of human behaviour. This will be analysed by drawing on the Lacanian concepts of acting out and passage à l'acte. The question then posed is: if both Milgram and Zimbardo claim that their work has emancipatory dimensions - a claim maintained within mainstream psychology - does a close reading of the studies not then reveal that psychology is, rather, the royal road to occurrences such as Guantanamo and Abu Ghraib? The drama of a psychology which is fundamentally based on a process of psychologization is that it turns its subjects into homo sacer of psychological discourse.
\end{abstract}

Introduction

George Miller, the cognitive psychologist, pleaded in his presidential address to the American Psychological Association in 1969 to 'give psychology away', claiming this would advance 'psychology as a means of promoting human welfare. ${ }^{1}$ Later, Miller described Milgram's experiments together with Zimbardo's Stanford Prison Experiment,

${ }^{1}$ G. A. Miller, "Psychology as a means of promoting human welfare." 
as "being ideal for public consumption of psychological research." Indeed, both Milgram's and Zimbardo's experiments are clearly meant to be disseminated to a broad audience, in fact, didactic and prophylactic objectives seem to permeate each entire experiment from the outset. Miller's appreciation of their importance justifies a close reading of the experiments to further our understanding not only of the field of social psychology but of psychology as a whole. Milgram and Zimbardo are indeed ideal, to understand the place of psychology in late-modern globalized culture. On the one hand these experiments are widely known which contributed towards psychology becoming one of today's hegemonic discourses - or to use the words of that other APA president, Ronald Levant - they saw to it that psychology became a 'household' word. ${ }^{3}$ On the other hand, the two experiments are not merely examples of psychologization processes, they also permit us to gain insight into the logic of the phenomena of postwar psychologization. In this way they can be seen as paradigmatic experiments. Hence, the fact that in textbooks the two experiments are invariably mentioned in the same breath not only points to an underlying similarity but also, as this article aims to show, reveals a more intricate and truly paradigmatic relationship between them. Thus, we can argue that beyond the historical link, Milgram and Zimbardo constitute the two logical times of the paradigm of postwar psychologization: Zimbardo's prison experiment was logically the necessary follow-up to Milgram's experiment. But before we engage with the experiments, we first have to address a preliminary question which will guide us through the rest of this article: how can we understand processes of psychologization? Are they simply the overflow of psychology into society, or do they tell us something particular about the status of the science of psychology as such? In the following section a first conception of psychologization is mapped out to guide us through the Milgram and Zimbardo analysis.

\section{Psychology and Psychologization}

Let us begin by questioning the effectiveness of Milgram's and Zimbardo's experiments in having become part of our household imagery. Richard Katzev, for example, argues that the increasing public awareness of Milgram's research and experiments on obedience in no way enlightened the people. Subsequent replications of the experiment

\footnotetext{
${ }^{2}$ Cited in: T. Blass, ed. Obedience to authority: Current perspectives on the Milgram paradigm (New Jersey: Mahwah, 2000), 208.

${ }^{3}$ R. F. Levant, "Making psychology a household word," The Psychologist 20, no. 6 (2007).
} 
found no systematic decline in obedience over time, despite the extensive coverage of the experiments in the media and the many public and academic discussions. ${ }^{4}$ Furthermore, for Katzev, experiments that first disclose psychological findings on, for example, defusion of responsibility - the theory that, when in groups, people feel less responsible for giving help to those in distress - demonstrate that informed subjects are not more helpful than uninformed subjects. ${ }^{5}$ There are, however, two problematic aspects with this approach which immediately brings us to the issue of psychologization. First, does it not leave us with a strange dualism? On the one hand, there is 'man' susceptible to be driven by emotions, authority claims and situations; in short, primitive, natural, preenlightened humankind. On the other hand, 'man' can also hold an enlightened position, reflecting on what science says about his Mr Hyde side - even if this reflection proves quite pointless. The question then is, where is the pineal gland? Or, in more contemporary terms, what is the interface between humankind's informed (and impotent) psychological gaze and humankind's psychological substantiality as such? The second problem is that Katzev apparently overlooks that there are unequivocal effects of the increasing public dissemination of psychological theories, namely a thorough psychologization of our life-world and society. Consider how K. J. Gergen observes how liberal education entails familiarity with central ideas of psychology, how higher education confronts vast numbers of students with course offerings in the field of psychology, how the mass media, speciality magazines and the soft-cover book market inform the broad public with psy-knowledge and, finally, how the major institutions in society (in the business, governmental, military and social spheres) rely more and more on psychological knowledge and personnel. ${ }^{6}$ Psy-knowledge, thus, does have effects. Furthermore, according to Gergen, psychologists are mostly not aware of what he calls the enlightenment effect, the fact that the dissemination of psy-knowledge modifies the patterns of behaviour upon which the knowledge is based.

Bringing together the two problematic aspects of Katzev's arguments, we can come to a preliminary conception of psychologization. Psychologization is the overflow of the knowledge of psychology into society altering the way in which 'man' is present with himself, others and the world. Psychologization is the process in which psychological signifiers and discursive schemes result in the typical dualism within modern humankind which reflects upon itself having adopted the academic, psychologizing gaze.

\footnotetext{
${ }^{4}$ R. Katzev, The Enlightenment Effect, Anecdote and Evidence: Essays Linking Social Research and Personal Experience (Philadelphia: Xlibris, 2002).

${ }^{5}$ R. D. Katzev and A. K. Averill, "Knowledge of the bystander problem and its impact on subsequent helping behavior," The Journal of Social Psychology 123, no. 2 (1984).

${ }^{6}$ K. J. Gergen, "Social psychology as history," Journal of personality and social psychology 26, no. 2 (1973).
} 
Let us, however, immediately push this definition to a problematic limit. For, if we depart from Gergen's conception of the enlightenment effect, are we not quickly led to the presupposition of a mythical original moment in which scientists could approach a still naive and virginal social and psychological reality? This would mean that it is only at a given point that the naive study of reality is over. That is, it is only at the close of an age of innocence that scientific knowledge feeds back into society and alters its reality. Gergen warns against the lure of approaching this new, enlightened reality with the same models and techniques we might have employed previously. However, is there not a danger that we could interpret this as first there was psychological 'man', and then came psychologized 'man'? Which would mean that psychologists would have to come up with more sophisticated research methods to unearth 'psychological man' beyond all the littering debris of psychologization. But then the question becomes, what would this essentialist psychology be worth if (post)modern 'man' is above all psychologized 'man' and not psychological 'man'?

The necessary step to avoid this essentialist paradox is to consider psychological 'man' as the founding myth itself of psychology. The modern subject constitutes itself in the very split of psychologized 'man' looking at psychological 'man': the new Narcissus having adopted the academic, psychological gaze, contemplates himself as being objectified and thus constructed by science. The cradle of modern subjectivity and of psychology is thus modernity and the advent of science. And here it is crucial to see that, historically, psychology came to light in a reality already objectified by the sciences. Psychology was an answer to the fact of humankind's life-world becoming more and more encroached upon by objectifying knowledge. In other words, the objectifications of science, charting every aspect of man's or woman's body, mind and environment, engendered what we might understand as the problem of subjectivity. The conceptualization of man as a machine, ${ }^{7}$ for example, creates the very problem of the ghost in the machine. ${ }^{8}$ This means that we are not dealing with a pre-given psychological subject resisting the objectivations of science; rather, the subject is what remains, it is the enigmatic leftover of the process of objectivation. ${ }^{9}$ It is here that psychology was seen to be needed. Psychology promised to (re)connect humankind with the Enlightened world, to find a new place for man and woman in a new world. In brief, psychology itself is the very interface between 'man' and an objectified world. Here it is already clear that there can only be a close relation between psychology and psychologization. The overflow of psychologization is thus not only secondary: the modern subject as such is a psychological being, a subject of the

\footnotetext{
${ }^{7}$ J. O. La Mettrie, Machine man and other writings.

${ }^{8}$ See also J. De Vos, "From La Mettrie's Voluptuous Man Machine to The Perverse Core of Psychology."

9 See also: J. De Vos, "On cerebral celebrity and reality TV. Subjectivity in times of brain-scans and psychotainment," Configurations (2010, in press).
} 
sciences, fundamentally touched by the academic reflexive gaze. In this way the radical conclusion seems to be that the overflow of psychology to society and its looping effects are the very fundamental dynamics of psychology. This would suggest that psychologization is the very way in which the discourse of psychology constitutes itself.

This view could shed new light on Milgram's and Zimbardo's seminal experiments and their important and paradigmatic meaning for the process of late-modern psychologization. While from a naive perspective on psychologization they are inaugural experiments, still treading on virgin terrain, a closer analysis reveals how, in both studies, psychology itself plays the leading role, showing how psychology is always and already looped psychology. But while both experiments can be read as examples of the structural link between psychology and psychologization, we shall argue that Zimbardo is the necessary complement of the Milgram experiment. The classic reproach to Milgram - that his experiment is foremost an enactment and a dramatization of the issue of obedience - only achieves full meaning in Zimbardo's experiment. Zimbardo's essentialist fantasy, his claim to have unravelled in his experiment the crucible of human behaviour, is but an, equally enacted, encounter with the reality of man, with psychological 'man'. The conclusion will be that Zimbardo's experiment was needed to bring the paradigm established by Milgram to closure. Milgram's paradigm, of a psychology relying on the psychologization of its subject matter, needed Zimbardo's enacted discovery of the crucible of human behaviour to ground it. ${ }^{10}$

Milgram's Shocking Answers as an Acting Out

In Stanley Milgram's experiment on obedience a naive subject found himself in a room together with another person who was actually a confederate of Milgram's. An experimenter in a grey lab coat told them that they would take part in a learning experiment to study the effects of punishment on learning. A rigged draw assigned the naive subject the role of teacher and the confederate the role of learner. The latter was strapped into a chair with one arm connected to the so-called shock generator. The teacher, in the baseline condition of the experiment, was seated in an adjacent room behind a switchboard. He was instructed to conduct a word-pair test via the intercom and to punish each wrong answer with an electric shock, increasing the shock by one level after

\footnotetext{
${ }^{10}$ I have written extensively on the Milgram experiment elsewhere (J. De Vos, " 'Now That You Know, How Do You Feel?' The Milgram Experiment and Psychologization."); the present article will therefore deal relatively more with Zimbardo.
} 
each failure. The experimenter, in his lab coat, was seated behind the naive subject and, whenever the test subject protested or refused to go on, he would intervene with prescripted phrases such as the experiment requires that you continue.

In an attempt to understand the horrors of the Nazi epoch, the experiment was devised to study people's willingness to obey an authority figure who gives instructions which conflict with their personal conscience. ${ }^{11}$ While Gordon W. Allport called it the Eichman Experiment, Milgram himself indicated that Hannah Arendt's conception of the banality of evil came closer to his own experimental findings. ${ }^{12}$ The first thing we need to look more closely at, then, is how Milgram understands or, better, stages authority. Yannis Stavrakakis contends that Milgram understood that it is not the substance of the command but the source of authority that is decisive. This source is supported by a scenario, or, as Stavrakakis puts it in Lacanian terms, by a fantasy scenario. For Stavrakakis it is clear that the phantasmatic frame in the experiment is science itself. The command is taken seriously by the naive subject insofar as it comes from Scientific Research.$^{13}$ It is already clear here that the subjects are not actually naive in the sense that they would be pre-Enlightenment creatures unschooled in the ways of science. They are already addressed as subjects familiar with and marked by science. Milgram, obtaining obedience with academic currency, however, does not think this through. He chooses science as a mere contingent example of authority, suggesting that he also could have used military or religious authority. ${ }^{14}$ This choice becomes particularly problematic when he additionally chooses psychological science (the subjects are told they are participating in a experiment on the psychology of learning) as the focus of the experimental set-up. In this way the experiment is pervaded by all kinds of unquestioned loops.

Quite surprisingly, these short-circuits are missed in mainstream critiques and, in this way, the real problematic core of Milgram's experiments remains out of sight. While the experiments have been criticized as a mere triumph of social engineering ${ }^{15}$ or as a mere dramatization of people's capacity for violence, ${ }^{16}$ the question of what exactly it is that is being enacted in the experiment seems to be forgotten. Let us turn here to the Lacanian concept of acting out. In psychoanalysis, acting out, as distinguished from memory or a symptom, involves an enactment of repressed material. In psychoanalytic practice the occurrence of an acting out is invariably linked to what one could call a dis-

\footnotetext{
${ }^{11}$ S. Milgram, Obedience to authority (London: Tavistock, 1974), 114-15.

${ }^{12}$ Ibid., 6.

${ }^{13}$ Y. Stavrakakis, The Lacanian Left. Psychoanalysis, theory, politics (Edinburgh: Edinburgh University Press, 2007), 175.

${ }^{14}$ S. Milgram, Obedience to authority: 142.

${ }^{15}$ E.g. Edward E. Jones, cited in: I. Parker, "Obedience," Granta 71, no. 4 (2000): 112.

${ }^{16}$ A. Brannigan, The rise and fall of social psychology (New Jersey: Aldine Transaction, 2004).
} 
cursive deadlock. The analysand has to take recourse to an enactment of that which, in his or her relationship to the psychoanalyst, cannot be said. Could this shed more light on the Milgram experiment? Central to the Lacanian concept of acting out is the enacting of the fundamental fantasy. ${ }^{17}$ Here Stavrakakis has already pointed out that Milgram's authority is based on the fantasy scenario of science. To this, I have added that psychology in particular constitutes the phantasmatic frame providing the script for the Milgram experiment. But before we tackle the question of the why - to which discursive deadlock the experiment responds - let us first discern how the scenario runs and, secondly, which roles or discursive positions are played out.

Concerning the baseline of the scenario, the key is to understand the didactic candidcamera moment when Milgram himself enters the room to lift the veils of deception, disclosing the learner as a confederate. The paradox is that, while Milgram wanted to show that obedience to authority is situational, in the moment of revelation the core of the experiment is revealed to be, surprisingly, individual psychology. In the postexperimental de-briefing the use of standard questions such as Do you feel upset?, What did you feel?, or Now that you know, how do you feel? shows how Milgram has ended up psychologizing the issue of obedience. In this way the candid-camera moment reveals the gaze of the big Other of academia. The experiment is the enactment of itself and of psychology, as it invites its participants to subject themselves to the discourse and signifiers of the psy-sciences. This is how we can understand Milgram's triumphant proclamation that the participants on the whole viewed the experiment as an opportunity to learn something about themselves and the conditions of human action. ${ }^{18}$ Milgram's experiment thus shows that looping effects in psychological research are not secondary but primary. Or, with Milgram, psychologization is the means by which psychology asserts itself as a science. And it does so through dramatization or, in psychoanalytic terms, through an acting out.

Let us now turn to the roles and the subject positions at play in the enactment. To start with, the naive test-subject is, surprisingly, put in the role of an experimental learning psychologist carrying out a word-pair test. While it is rather illogical to be asked to conduct an experiment, strangely enough not one of the participants questions this. Perhaps we have 100 per cent obedience here because the assignment of this role simply repeats general psychologization processes in which everyone is turned into a proto-psychologist and encouraged to adopt a scientific gaze. But, more importantly, is it not exactly in the role of psychologist that the subject is situated as the obedient bureaucrat inflicting torture and pain?

\footnotetext{
${ }^{17}$ F. Koehler, "Melanie Klein and Jacques Lacan," in Reading Seminars I and II: Lacan's Return to Freud, ed. R. Feldstein, B. Fink, and M. Jaanus (Albany: Suny Press, 1996), 116.

${ }^{18}$ S. Milgram, Obedience to authority: 196.
} 
Whether Alfred McCoy was right or not in claiming that the Milgram experiment was funded with CIA money, implying the direct connection with the CIA's infamous mindcontrol project, ${ }^{19}$ this is not so important in view of the fact that the experiment as such is a theatrical inauguration of psychologists assisting in torture. However, to return to the Milgram experiment, if it is 100 per cent obedience that we are looking for, there might be a much easier place to find it. Did Milgram not get his 100 per cent obedience from the experimenter who instructed the test-subject with his monotone prompts such as You have no other choice, you must go on. Milgram's film footage shows an experimenter mechanically and emotionlessly repeating his scripted phrases while the obviously agitated and stressed subjects express their desire to stop. ${ }^{20}$ So, while Milgram dismisses the Freudian explanation of aggressive and destructive tendencies, ${ }^{21}$ do these not reemerge unexpectedly on the side of the experimenter? One must conclude that the obedient bureaucrat-torturer was already written into the experiment. As Dannie Abse suggests, Milgram, looking for little Eichmans, constructed a scene with an experimenter in the role of Himmler. ${ }^{22}$ This leaves us with Milgram's own role. Is he not the figure of the ultimate malevolent scientist collecting from his participants the surplus-value of his scripted experiment? His post-experimental Now that you know, how do you feel? is meant to harvest the psychologizing answers to make his case on obedience. Furthermore, in the same movement, Milgram's subjects get de-subjectivized as they are reduced to the obedient objects of the power of psychological knowledge. Milgram reports proudly that a large number of subjects spontaneously requested to be used (sic) in further experiments. ${ }^{23}$ Consumed in the candid-camera moment, the test-subjects become the mere objects of the psy-sciences. The introspective moment in which the experiment culminates reveals nothing but the pre-scripted analysis. Milgram's promised emancipation from blind obedience is actually a mere enactment of the powerful and unemancipatory discourse of psychology.

Having discerned the different roles being played in Milgram's acting out, we can now address the question of why? In clinical terms there are always reasons why an acting out emerges instead of a memory or a symptom. It is useful to start here with Lacan's argument that both acting out and a passage à l'acte are attempts to ward off anxiety. In contrast to a passage à l'acte, however, there is still a relationship at play in acting out. The

\footnotetext{
${ }^{19}$ A. W. McCoy, A question of torture: CIA interrogation, from the Cold War to the War on Terror, vol. Metropolitan Books (New York, 2006).

${ }^{20}$ S. Milgram, "Obedience," (University Park , PA: Penn State Audio Visual Services, 1965).

${ }^{21}$ S. Milgram, Obedience to authority: 165.

${ }^{22}$ Cited in: A. Brannigan, The rise and fall of social psychology.

${ }^{23}$ S. Milgram, "Some conditions of obedience and disobedience to authority," Human Relations 18, no. 1 (1965): 58.
} 
subject still calls upon the Other to respond to his or her act. ${ }^{24} \mathrm{~A}$ typical example is the attempted suicide which functions as a cry for help. The relational aspect is also clear in the fact that acting out is almost invariably preceded by a significant other having not heard or not answered some earlier appeal or message. If Milgram's experiments are an example of acting out, then the anxiety at play can, as noted above, be linked to Arendt's notion of the banality of evil. The relational deadlock - in psychoanalytical terms the deadlock of transference - is, then, a deadlock in understanding the Holocaust. Academia - functioning as the Big Other in modernity - has fallen short of even the beginnings of an understanding. Milgram's experiment can thus be understood as the construction of a scene in which the big Other of science is (re)installed as an agency which will deliver the proper interpretation. Milgram's shocking answers (Zimbardo's quip) are staged in order to deal with the incomprehensible horrors of the Holocaust. The experiment is the mise-en-scène of 'man' as an easily manipulated and naive everyday subject who can be saved and redeemed by science. In Lacanian terms, this would be the subject as objet $a$ : the cause and object of the desire of the Other.

The problem with acting out, however, is that when it is not interpreted (not worked through, in Freudian terms) there is always the threat of its culminating in a passage $\grave{a}$ l'acte. Repeated suicide attempts, for example, can suddenly lose their relational dimension and shift to a real step beyond the relational scene. However, this does not necessarily entail a definite exit from the scene. It can also be a momentary dissolution of the subject and of the social bond. In the meantime what manifest are instances of brute force (fights, suicide ...), flights from the dimension of the Other to the dimension of the Real..$^{25}$ This brings us to Zimbardo's claim that the Stanford Prison experiment offers us a window onto the brute force of humankind. Zimbardo's main argument is that he was carried away in the set-up of his own experiment but this loss of control is actually what discloses the 'truth' of human interaction. Translated in psychoanalytic terms this would be to say that Zimbardo was caught up in an acting out (being carried away in the role of his own script) which eventually tilted over into a passage à l'acte, revealing the Real of the human subject in an unmediated way.

\footnotetext{
${ }^{24}$ J. Lacan, Le séminaire, Livre X: L'angoisse, 1962-1963 (Paris: Seuil, 2004).

${ }^{25}$ D. Evans, An introductory dictionary of Lacanian psychoanalysis: 137.
} 
Historically, Zimbardo's prison experiment cannot be seen apart from Milgram's experiment on obedience. ${ }^{26}$ Zimbardo himself recognizes his indebtedness to Milgram and acknowledges various parallels between the Stanford Prison Experiment and Milgram's research on obedience. ${ }^{27}$ Nevertheless, Zimbardo's experiment contests Milgram's thesis that authority is central in phenomena of obedience and puts forward the thesis that people blindly enact what is expected of them in their role as group members. In this section I will explore the parallels and the differences between the two pieces of research and try to assess in which ways Zimbardo is departing from the Milgram paradigm only, as we will see, to return to it in the end. My focus is thus not so much the historical link, but rather, the paradigmatic link, which, as I will claim, can be understood as follows: Zimbardo's experiment is the necessary logical sequel to Milgram's experiment.

To begin with, perhaps the most striking parallel between Milgram and Zimbardo is how the discourse of psychology - and even the signifier psychology as such - occupies a central, albeit unquestioned, place in both experiments. That said, considering their respective advertisements to recruit participants, something has clearly changed in the time between the two studies. While Milgram needed people "for a study of memory", Zimbardo recruited explicitly for "a psychological study of prison life" (emphasis added). With Milgram it may have been clear to the participants that the experiment was situated within science, but it is only at a particular moment that psychology itself entered the scene, with the question Now that you know, how do you feel? It is only here that the subject is explicitly drawn into psychological discourse. As such, the Milgram experiment illustrates the shift in late-modernity from the master discourse (with a master figure as the agent) to the university discourse (where knowledge itself is the agent). Milgram's psychologizing question Now that you know, how do you feel? leaves behind the old master, exemplified in the authoritative figure in the lab coat, and opens the way for the university discourse, in which the knowledge of the psy-sciences takes the prominent role. Milgram, in this way, does indeed conduct an experiment on obedience. He shows or, better, enacts how, in the psychologization processes of late modernity, humankind is called upon to subject itself to the psy-sciences. Zimbardo takes this logic one step fur-

\footnotetext{
${ }^{26}$ In his book The Lucifer Effect Zimbardo amply discusses the Milgram experiment, noting also his personal acquaintanceship with Stanley Milgram (P. Zimbardo, The Lucifer Effect (New York: Random House, 2007), 518. ${ }^{27}$ See especially P. Zimbardo, "The Power of Norms and Groups on Individuals: Parallels Between the Stanford Prison Experiment and Milgram's Obedience Research.," http://www.lucifereffect.com/about_content_norms.htm.
} 
ther. With Zimbardo, psychology is no longer called upon to structure the scene in a second moment. From the very beginning the scene is set within a psychological discourse: "male college students needed for psychological study of prison life."

So where Milgram has his psychologizing de-briefing moment, Zimbardo has his psychologizing pre-briefing. The selected students were divided randomly into guards and prisoners, and the first group had to attend a so-called guard orientation meeting the day before the actual experiment. There Zimbardo addressed the guards:

You can create in the prisoners feelings of boredom, a sense of fear to some degree, you can create a notion of arbitrariness that their life is totally controlled by us, by the system, you, me - and they'll have no privacy. ... We're going to take away their individuality in various ways. ... We have total power in the situation. They have none. ${ }^{28}$

This is surely quite directive. However, Zimbardo's co-researcher Craig Haney strongly downplays this, repeating several times that the guards were only told that they were not allowed to use physical punishment or aggression. ${ }^{29}$ Also Zimbardo invariably minimizes this step. In his latest book, The Lucifer Effect, he maintains that the guards' orientation did not encourage them to follow a prescribed path. ${ }^{30}$ But while this passage is criticized by many authors, ${ }^{31}$ surprisingly none of the critics appear to see that the participants are effectively asked to take on the role of experimenter. Zimbardo literally tells the guards that it is up to them to produce the "required psychological state in the prisoners." ${ }^{32}$ There is no doubt that the experiment is scripted, but we should not miss the fact that the script is psychological. The student-guards are asked to play the role of social scientists conducting an experiment. Banyard is right in stressing the awkward use of the pronoun we in we have total power ${ }^{33}$ but this should not be understood as we the guards but, rather, as we the psychologists. ${ }^{34}$ While with Milgram we have a similar sce-

\footnotetext{
${ }^{28}$ P. Zimbardo, "Quiet rage: The Stanford prison study video," (Stanford, CA: Stanford University Press, 1989), my transcription.

${ }^{29}$ C. Haney, C. Banks, and P. Zimbardo, "A study of prisoners and guards in a simulated prison.," in Readings about the social animal, ed. E. Aronson (San Franciso: Freeman, 1981).

${ }^{30}$ P. Zimbardo, The Lucifer Effect: 54.

${ }^{31}$ E.g. P. Banyard, "Tyranny and the tyrant. Zimbardo's 'The Lucifer Effect' reviewed," The Psychologist 20, no. 8 (2007); A. Brannigan, "Review: The Defense of Situationalism in the Age of Abu Ghraib," Theory \& psychology 19, no. 5 (2009); S. A. Haslam and S. D. Reicher, "Questioning the banality of evil," The Psychologist 21, no. 1 (2008).

${ }^{32}$ P. Zimbardo, The Lucifer Effect: 55, emphasis added.

${ }^{33}$ P. Banyard, "Tyranny and the tyrant. Zimbardo's 'The Lucifer Effect' reviewed."

${ }^{34}$ Furthermore, we should note that not only did the group of guards comprise volunteers, but the role of warden was played by an undergraduate research assistant while Zimbardo himself took the role of superintendent.
} 
nario of the test-subject being put in the place of the scientist, Zimbardo brings this scheme to a logical completion. The Milgram experiment does not really involve role play. The naive subject agrees to perform an assignment in which he effectively remains himself (in the naive sense). It is only at the end that it is disclosed that he has been playing a role. With Zimbardo it is all out in the open. Not only is it clear who is playing which part, but it is also clear to everybody that it is all a role play. The essential trick of role play is the staged lucidity within a redoubled role. Zimbardo's students are not so much instructed to play guards. Rather, they are instructed to play psychologists pretending to be guards.

Another point of comparison between the experiments concerns the role of the victim. Zimbardo's shift here is to introduce the role of the prisoner, where he effectively fleshes out the victim-role which in Milgram was still played by a confederate. But there is something particular to be discerned in this shift. For, do we not find here another instance of something that remained concealed with Milgram being laid bare with Zimbardo; namely the aspect of humiliation? With Milgram humiliation is implicit and only emerges in the de-briefing, where the test-subject is confronted with his reprehensible behaviour and reduced to a mere object of social psychology. In this way, the ingenious and powerful science of psychology manages to extract from the test-subject valuable knowledge concerning the true nature of humankind - which of course bears a structural resemblance to the use of torture to obtain information. In Zimbardo's experiment, however, the humiliation is made explicit and primary as it shifts to the category of the prisoners. This is how Haney and Zimbardo describe their induction:

A degradation procedure was designed in part to humiliate prisoners and in part to be sure they weren't bringing in any germs to contaminate our jail. The prisoners were deloused and decontaminated, they were made to wear baggy uniforms without underwear, they had to wear stocking caps to conceal their hair ...

This de-humanization and de-subjectivation of the prisoners had started already with the staged arrests, as the students were unexpectedly picked up at their homes by local police officers while surprised and curious neighbours looked on and then, blindfolded, they were driven "in a state of mild shock" to the "Stanford County Jail." ${ }^{36}$ Initially the

\footnotetext{
${ }^{35}$ C. Haney, C. Banks, and P. Zimbardo, "A study of prisoners and guards in a simulated prison.."

${ }^{36}$ Here another difference with the Milgram experiment emerges. If Milgram's experiment leant on the format of candid camera - with the experiment culminating in the moment of disclosure of the deception - the Stanford Prison Experiment is much closer to the format of reality television. Consider how the surprise Sunday arrests were filmed (by actual network stations Zimbardo managed to involve) and how the rest of the experiment was watched over by cameras, prefiguring the huit clos of shows like Big Brother (for the role of the mass media in relation to the processes of psychologization see J. De Vos, "On cerebral celebrity and reality TV. Subjectivity in times of brain-scans and psychotainment.").
} 
regime is quite mild and things only start to unravel on the second day. The prisoners remove their stocking caps, rip off their numbers and barricade themselves inside the cells. Zimbardo writes that he was stunned. He had not expected a rebellion and it was not clear to him what they were rebelling against. But, one is tempted to see Zimbardo's surprise as feigned: for were not these kinds of events what he had hoped for? Moreover, in his being stunned, Zimbardo misses how this seemingly spontaneous rebellion was discursively structured, as the participants shouted:

A fucking simulation! It is a fucking simulation, it is a fucking simulated experiment! ${ }^{37}$

Given the fact that the rules forbade the prisoners to refer to their condition as an $e x$ periment or a simulation, the rebellion above all seems directed against the simulation of the experiment itself. Whether the students really had enough of the experiment, as Banyard suggests, ${ }^{38}$ is perhaps not really the point. That they shouted "Fuck this experiment. And fuck Dr. Zimbardo!" ${ }^{39}$ should have made Zimbardo understand that he was receiving his own message in an inverted form - an essential trope in communication according to Lacan. ${ }^{40}$ Zimbardo, however, remains deaf to the looping of the theoretical framework of social psychology which contaminates the whole experiment. He remains convinced that he sees the 'real thing' and does not appear to understand the dynamics of his own script. With Milgram the script entailed the juxtaposition of authority and conscience, which was then transcended by the psychologizing disclosure of the de-briefing. Zimbardo, on the other hand, begins with the assumed power of psychological discourse itself and what results from this is the creation of an opposition between those within this discourse and those outside it. In other words, while the guards' orientation constitutes a class of those informed by psychology, in the same movement, it constitutes the prisoners as the humiliated and debased homo sacer of the psychological discourse. For Giorgio Agamben, ${ }^{41}$ a discourse of power always produces a class of excluded-included. Homo sacer is banned from the ruling order but nonetheless totally defined by it. ${ }^{42}$

\footnotetext{
${ }^{37}$ P. Zimbardo, "Quiet rage: The Stanford prison study video," my transcription.

${ }^{38} \mathrm{P}$. Banyard and C. Flanagan, Ethical issues and guidelines in psychology (New York: Routledge, 2005).

${ }^{39}$ P. Zimbardo, "Quiet rage: The Stanford prison study video," my transcription.

${ }^{40} \mathrm{~J}$. Lacan, Ecrits: A selection (London: Tavistock, 1977), 85.

${ }^{41} \mathrm{G}$. Agamben, Homo sacer.

${ }^{42}$ For example, Europe, as a juridical-sovereign order, produces the sans-papiers. They are not a part of the legal order but, nonetheless, they are defined by it. In this very way the sans-papiers function as a guarantee of that order.
} 
This is precisely what Reicher and Haslam miss in their BBC Prison Study. ${ }^{43}$ Their study challenges Zimbardo's theory that behaviour is determined by assigned roles. Reicher and Haslam criticize the underlying message here that resistance is futile. Consequently, the BBC Prison Study focuses on 'the manipulations of theoretically relevant variables' rather than assigned roles. Summarizing their findings, Reicher and Haslam state that it is powerlessness and a failure of the group that makes tyranny psychologically acceptable. That these results seem to 'prove' what had to be proved is not the issue here. Far more important is that Reicher and Haslam psychologize the situation even more than Zimbardo. Every day, the participants were subjected to psychometric testing and 'swabs of saliva' were taken in order to ascertain cortisone levels. They knew they were being video-- and audio-recorded at all times (the experiment was broadcast as a reality TV show) and that two independent clinical psychologists were monitoring the study throughout. Is this not the paradox of psychology as the ultimate tyrannical Big Brother? The remark of one of Zimbardo's participants that the Stanford Prison was "a prison run by psychologists," ${ }^{44}$ gets fully realized with Reicher and Haslam. In controlling every theoretically relevant variable, they assess and control even the psychosocial determinants of the emancipatory potential. In this way, the homo sacer position of Zimbardo's prisoners is effectively generalized with Reicher and Haslam. Every participant is the excluded-included subject of the hegemonic psychological discourse and it is this that provides the rationale and the ultimate guarantee of the discourse. But staging absolute control makes Reicher's and Haslam's experiment rather dull since it cannot really provide anything like Zimbardo's high-pitched dramatics.

In Zimbardo's experiment it gradually becomes clear that the psychologizing of the guard-prisoner opposition is the very motor of the drama. While Milgram himself did the psychologizing, with Zimbardo this task is assigned to his participants. This is how we can understand that, after crushing the initial rebellion, the guards announced that they were going to resort to "psychological tactics instead of physical ones." This is, of course, nothing more than the signifier psychology taking yet another tour on the merrygo-round of the experiment, preparing us for yet another turn, as the brutal guard nicknamed 'John Wayne' takes centre stage. In the next section this figure will be the point of departure to question whether Zimbardo's experiment is equally, as with Milgram, an acting out or, rather, a passage à l'acte.

${ }^{43}$ S. Reicher, "Rethinking the psychology of tyranny: The BBC prison study," The British Journal of Social Psychology 45, no. 1 (2006).

${ }^{44} \mathrm{P}$. Zimbardo, The Lucifer Effect: 160. 
From acting out to passage à l'acte ... and back again

'John Wayne' exemplifies for Zimbardo "the point in time when an ordinary, normal person first crosses the boundary between good and evil," 45 and thus illustrates that it is not authority, as in Milgram's experiment, but role assignment which explains obedience and consequent reprehensible and shocking behaviour. Many commentators focus on 'John Wayne' to launch critiques of the experiment as a pre-scripted role play. Zimbardo eventually concedes that acting was the first step in the student Dave Eshleman's becoming 'John Wayne' but he argues that, by living the part for eight hours a day, Eshleman began 'internalizing his character. ${ }^{46}$ Is Zimbardo's experiment then also to be understood as an acting out? If so, the questions are again: what is the baseline of the scenario and who plays which parts?

Eshleman's own explanation was that he drew his inspiration from the fraternity hazing he had just gone through:

And a lot of these things I'm sure just sort of popped into our heads to see, you know, we were kind of testing the limits. You know they did anything we told them. Where's the point where they would stop and object? ${ }^{47}$

If we take this seriously, then this puts a big question mark over Zimbardo's claim that the behaviour 'John Wayne' displayed can be understood as authentic and independent of the experiment itself, for hazing always takes place in the absence of any official agent of authority. Those conducting the hazing act to test the limits of the authority they have temporarily assumed and exercise this authority against an anonymous freshman. ${ }^{48}$ Slavoj Žižek points out that in hazing the mimicking of the absent authority clearly reveals the obscene underside, the obscene surplus already present in the regular authority. ${ }^{49}$ In order, then, to discern what kind of authority is really being mobilized in the Stanford Prison Experiment, Eshleman's remarks are very helpful. In an interview he explains that he was acting to help Zimbardo get results. He tells us that the first night he was struck by the fact that everybody was treating the study like summer camp:

45 P. Zimbardo, "Who was Lucifer and how did he become the Devil," http://www.lucifereffect.com/lucifer.htm.

${ }^{46}$ Cited in: A. Zarembo, "A Theater of Inquiry and Evil," Los Angeles Times, July 152004.

${ }^{47}$ A. Cooper, "New Photos of Iraqi Prisoner Abuse Released; Bush Backs Rumsfeld," in 360 DEGREES (CNN, 2004).

${ }^{48}$ This is maybe why Zimbardo took the role of superintendent. In doing so, he could join the guards and create a band of brothers. Consequently, the real authority at stake in the experiment, Academia, is displaced.

${ }^{49}$ S. Žižek, "What Rumsfeld Doesn't Know That He Knows About Abu Ghraib," In These Times, 2004, 21 June 2004. 
... I decided that nothing was really happening in this experiment and that in order for this experiment to get any results that somebody had to start to push the action and I took it upon myself to do so. ${ }^{50}$

Strangely enough, almost the same words return with Zimbardo:

On the first day, I said, this is not gonna work. I mean, the guards felt awkward, giving orders. And they'd say, okay, line up, and repeat your numbers. And the prisoners would [start] giggling. ${ }^{51}$

This is not the only discursive short-circuit. Zimbardo states that he borrowed the idea of the guards wearing sunglasses from the movie Cool Hand Luke ${ }^{52}$ and then Eshleman mentions the same movie as the inspiration behind his prison guard character. ${ }^{53}$ Is this a case of trading places? Is 'John Wayne' the uncanny double of Zimbardo, revealing a problematic core of the psy-sciences? Eshleman, for example, argues that he was running a little experiment on his own. Concluding that the experiment was put together to prove a point about prisons being cruel and inhumane places, Eshleman decided 'to help those results come about. ${ }^{54}$ In this sense, the brutal 'John Wayne' appears as the gestalt of the mad scientist. ${ }^{55}$ So if the experiment reveals something about evil, as Zimbardo claims, is this not about evil emerging in the relation between the social and human sciences and the discourses of power? Evil is, then, the inevitable dark side, the underlying truth of a discourse which claims to be human and to do good. In Milgram's experiments this was acted out in different places. It first appears with the test-subject who, in his role of experimental psychologist, is lured into bureaucratically performed cruelty. It is then located with the experimenter who, as a mad scientist, presses the poor, naive testsubject to continue. Finally, it is located with Milgram himself, as he enters the room to disclose the experimenter as the embodiment of malevolent science and to exchange the master discourse with the university discourse. Here Milgram proves to be the ultimate demiurge; having extracted the valuable knowledge from his subjects, he leaves them

\footnotetext{
${ }^{50}$ A. Cooper, "New Photos of Iraqi Prisoner Abuse Released; Bush Backs Rumsfeld."

${ }^{51}$ Sundance Channel, "The Human Behavior Experiments," (2006).

${ }^{52}$ C. Haney, C. Banks, and P. Zimbardo, "A study of prisoners and guards in a simulated prison.."

${ }^{53}$ A. Cooper, "New Photos of Iraqi Prisoner Abuse Released; Bush Backs Rumsfeld."

${ }^{54}$ A. Zarembo, "A Theater of Inquiry and Evil." When I asked Dave Eshleman if he was interested in psychology at that time and knew of the Milgram experiment he replied: "I had no special interest in psychology when I participated in the experiment. I was majoring in music at the time. I had heard of Milgram's experiment but it had no influence on me during the experiment" (personal correspondence).

${ }^{55}$ Concerning the role of Academia in the cruelty of the Stanford Prison Experiment, we should perhaps consider the fact that the degrading hooding, an image returning in the Abu Ghraib photographs, was the experimenters' idea, not the guards. It was their solution to the problem of how to lead the prisoners to the toilets, which were outside the confines of the prison yard, without breaking the sense of an enclosed environment.
} 
behind, humiliated and subjected to a pseudo-emancipatory psy-discourse. Zimbardo's experiment takes up the issue where Milgram leaves off, showing what happens when the scenario operates entirely under the university discourse. It is in this context that we have to understand Zimbardo's excuse for having inflicted real pain on his participants. He admits that he got carried away in his role and was beginning to think like a prison superintendent rather than a research psychologist. ${ }^{56}$ Is not this contention, however, which we can translate as a claim to having been drawn into an acting out, the ultimate excuse for not having to deal with his problematic role as experimental psychologist? Maybe we should simply hold Zimbardo responsible for being carried away as a psychologist, especially where, on top of acting out, he claims to have assisted in a momentary disclosure of the crucible of human behaviour - or, translated into Lacanian terms, he claims to have been caught in a genuine passage à l'acte.

The mark of the passage a l'acte is that the social bond, the dimension of the big Other, is suspended as the subject steps outside of symbolic, mediated reality and enters the Real. Typical instances of passages à l'acte would be suicides, outbursts of violence and fugues. These instances are a testimony of a subjective deadlock which cannot be mobilized via a recourse to a phantasmatic driven enactment or acting out, instead there is a disruptive and often violent stepping out of the scene. Could we not also add to this list, Zimbardo who is being drawn into a seemingly unmediated scene of brute and direct violence? When Zimbardo's girlfriend visits the experimental prison a strange and decisive moment takes place. Christina Maslach, who had just earned her doctorate in psychology under Zimbardo, is confronted from the open door of Zimbardo's superintendent's office with the 'toilet run chain gang', the line of hooded prisoners being led to the lavatory. Zimbardo urges her to look and relates her answer:

'I already saw it'. And she looked away again.

I was shocked by her seeming indifference.

'What do you mean? Don't you understand that this is a crucible of human behavior, we are seeing things no one has witnessed before in such a situation. ${ }^{57}$

Zimbardo seems convinced he is looking at bare life itself, showing his girlfriend the laboratory version of the Big Bang, the genesis of vibrating and pulsating life. Is this not the essentialist fantasy noted earlier: the presupposition of a mythical moment wherein the psy-scientist is able to see things as they are? Zimbardo himself thus appears as the sovereign, mad scientist with Frankenstein's life or the unmediated Real in his hands. It is here that we can see him as immersed in his own creation and himself drawn into a

\footnotetext{
${ }^{56}$ P. Zimbardo, "Stanford Prison Experiment Slideshow: A visit," http://www.prisonexp.org/slide-27.htm.

${ }^{57}$ P. Zimbardo, The Lucifer Effect: 169.
} 
seemingly genuine passage à l'acte. The rest of the story seems to back up this narrative. Christina Maslach looks away in disgust and understands that to pull Zimbardo back to reality she has to introduce love into the equation by making Zimbardo choose between the fascinating Siren-like crucible of human behaviour and her love in the actual world. Maslach describes how she told Zimbardo that he had become a stranger to her, that she did not recognize 'the caring and compassionate person' she once knew:

I'm not sure I want to, you know, have anything to do with you if this is the real you. $^{58}$

For Zimbardo this was a slap in the face, "the wake-up call from the nightmare that [he] had been living day and night for the past week," and he decided to call the experiment off. ${ }^{59}$ Maslach reports that a great weight was lifted from both of them and from their personal relationship. ${ }^{60}$ So, the story ends and they married and lived happily ever after.

However, if we do not accept Zimbardo's acting out (his claim that he was carried away in his role as superintendent) we should be equally wary of conceding that he was engaged in a passage à l'acte. For on a closer look, the thesis that Zimbardo is totally immersed in a passage à l'acte presents several problems. Does not, for example, the fact that Zimbardo asks his girlfriend to watch the prisoners being led to the toilet presuppose a relational dimension? A second clinical objection might be that one is rarely confronted with first-person elaborations of a passage à l'acte. As a rule the subject of a passage à l'acte would be left baffled and the events would usually be related or reconstructed by a third party. The idea that Zimbardo is engaged in a passage a l'acte thus becomes less and less plausible. Remember Zimbardo's hunch at the beginning of the experiment that it was 'not gonna work' (and Eshleman adding that somebody had to push the action). The experiment, which involved substantial expense, had to be saved, as did Zimbardo's career. Should the subsequent escalation not then be seen as a dramatization of "pushing the envelope," as Eshleman called it, to reveal the true face of humankind in a violent Armageddon? The dramatic passage à l'acte-like denouement of closing down the experiment might thus, above all, have served to bring the experiment to a nice conclusion, complete with Zimbardo's mea culpa. ${ }^{61}$ Instead of a step into the Real, this imagery brings us back to the stretched boundaries of symbolically mediated reality.

Zimbardo's account of the crucible of human behaviour thus returns us to a Milgramesque acting out. And then the question is once again, what is the fantasy scenario

\footnotetext{
${ }^{58}$ Sundance Channel, "The Human Behavior Experiments."

${ }^{59}$ P. Zimbardo, The Lucifer Effect: 170.

${ }^{60}$ Ibid., 171.

${ }^{61}$ I am indebted to Ian Parker (Manchester Metropolitan University) for these comments
} 
that underlies the image of Zimbardo standing at the edge of the abyss of humanity? Here Zimbardo, keen as he is on romantic imagery - just think about the imagery of The Lucifer Effect - might have been inspired by the Faustian mad scientist and the related Gothic theme of unravelling the secrets of life. There is some circumstantial evidence to support this idea. If the study can be understood to culminate in an all's well that ends well marriage, this theme is already redoubled in the experiment itself. At one point the guards stage a mock marriage featuring, most aptly, Frankenstein:

'Why don't you play Frankenstein. 2093, you can be the bride of Frankenstein. ... 7258 , you be Frankenstein. I want you to walk over here like Frankenstein, and say that you love 2093. ${ }^{62}$

'John Wayne' brutally shoves the prisoners together into an embrace, making them say I love you. Of course it can be argued that this mock marriage is a mere coincidence and that it would be stretching things too far to connect it to the personal story of Zimbardo. But is not this image of the monster created by science already lurking under the surface of the experiment, only to be brought to the surface by Eshleman who immediately sensed that the experiment was meant to bring out "the evils inherent in a prisontype environment?" ${ }^{33}$ The mock Frankenstein marriage thus seems to presage the fact that Zimbardo's mock prison drama could only ever end with the classical solution of bringing in the bride.

In this way we should resist the temptation to play down the Maslach episode, dismissing it as an aspect of Zimbardo's personal drama unhappily interfering with the experiment. On the basis of that assumption one could still claim that Zimbardo's experiment does touch on a real socio-psychological ground beyond the methodological flaws introduced by his personal history. ${ }^{64}$ But are these two aspects really separable? We should consider the following anecdote. On Zimbardo's website there is a video of him giving a Powerpoint presentation. When he comes to the Christina Maslach episode, he remarks, "The next day I stopped the experiment." The next slide is of their marriage photo and he comments, "... and the next year I was married to her." ${ }^{65}$ At this point the whole audience explodes in laughter and applause, as if relieved by the happy

\footnotetext{
${ }^{62}$ P. Zimbardo, "Quiet rage: The Stanford prison study video," my transcription.

${ }^{63}$ A. Zarembo, "A Theater of Inquiry and Evil."

${ }^{64}$ For Martha Nussbaum, for example, Zimbardo is far too emotionally involved for the resulting behaviour to be scientifically reliable (M. Nussbaum, "Texts for torturers. From Stanford to Abu Ghraib - what turns ordinary people into oppressors?," The Times Literary Supplement, October 17 2007.), which suggests that the scientific reliability of psychological research can be realized by restraining the subjective factor.

${ }^{65}$ P. Zimbardo, "How ordinary people become monsters ... or heroes," in TED Conference 2008: The Big Questions, February 27-March 1, 2008 (Monterey, California2008).
} 
end of the horror story: they married and had many children. Does this collective emotional release on the part of the audience not show that the conclusion of the Stanford Prison experiment saved more than just Zimbardo's experiment and his career? It saved a whole discourse and a particular approach within the psy-sciences, namely a psychology unable to assess its inevitable and structural link with psychologization.

\section{Conclusions}

The fact that Zimbardo's Prison Experiment boils down to a move from Milgram's acting out to a passage à l'acte and back again should not, however, obfuscate the important structural shift here. Milgram attempted to deal with the horrors of the Nazi era, as it was there that the western world was confronted with the deadlock of the project of Enlightenment and the impotence, or even complicity, of scientific discourse. Milgram's experiments are the mise-en-scène of the departure from the master discourse and the attempt to reground science within the university discourse, in which the subject becomes a psychologized subject, called upon to adopt a scientific gaze. Milgram shows us that this turn to the university discourse in late modernity structurally glides over the discourse of psychology and, thus, over the problematic status of subjectivity. This is, of course, the return of the inherent paradoxes of the modern Cartesian subject insofar as Descartes's endeavour was already an attempt to posit 'man' against the objectivizations of science. Descartes differentiated res cogito from res extensa as an attempt to constitute the subject, not as the sum of the objectivizations of science, but precisely as the remainder, the residue of the encroaching of science on man's Lebenswelt. As a result, subjectivity is the name of the problematic aspect of modernity. It is at this point that psychology arrives as the discipline which will take care of this problematic subject. Psychology aspires to be the meta-theory of science, resolving the breaches subjectivity causes in the constructions of science.

It was Edmund Husserl who already pointed out the problematic position of psychology when he claimed that psychology chooses the wrong option in trying to appropriate the same objectifying paradigms that engendered the problem of subjectivity. ${ }^{66}$ It can be claimed that Milgram is caught in the same paradox. In his experiment, the paradoxes of modern subjectivity do not only return, his experiment, moreover, shows how these paradoxes result in post-Second World War psychology being caught in a fundamental

${ }^{66}$ E. Husserl, The crisis of European sciences and transcendental phenomenology: An introduction to phenomenological philosophy. 
and structural psychologization. ${ }^{67}$ Milgram's paradigmatic experiment lays bare how psychology cannot but ground itself in an auto-enactment and the looping of a prescripted situation. George Miller's call to spread psychology in this way reflects mainstream psychology's choice to re-establish itself as a science via psychologization. In the experiments of both Milgram and Zimbardo, psychology is indeed given away, it is the very motor of the experiments.

This analysis shows that the underlying paradigm of a whole array of theoretical and practical approaches in contemporary psychology relies on feeding psychology into the field of research or the field of action. One telling example here is psychologization processes of children and youth: via all sorts of media and institutions psychology is given away to parents, teachers, educators, and last but not least to the children themselves. The psychologist-psychoanalyst Mary Lamia, for example, pleads for a "general psychological education" to extend "psychological knowledge and awareness" with preteen children. ${ }^{68}$ Here it is perfectly clear that psychologization follows the "now that you know ...' paradigm. For Lamia children have to be instructed

... to recognize and appreciate individual differences, be responsive to shared experiences among peers, become conscious of the complexity of human motivation, develop an awareness of appropriate responses to interpersonal situations, and identify the availability of choice in attitudes and behaviors. ${ }^{69}$

In short, the children are turned into little psychologists, little apprentices of psychology. This is the pre-condition for the second part of the paradigm: "now that you know, how do you feel?' As Lamia puts it, children should be able to "understand their behavior and emotions through the general perspective of a psychologist."70

While Milgram can be seen as setting up the scene, Zimbardo starts from the already scripted scene. There Zimbardo is pushed to find a way to ground and fix the looping of the script of psychology in a mythical heroic journey into the underground of the Real of 'man'. Zimbardo's enacted passage à l'acte was needed to affirm Milgram's paradigm. It is only with Zimbardo that the paradigm of psychologization grounded by Milgram gets its completion: as Zimbardo enacts the power of psychology to reveal 'man' as he really

\footnotetext{
${ }^{67}$ This is closely connected to the birth of the welfare state, in which the psy-discourses obviously play a central role. The later shifts of so-called post-fordism - in which immaterial production according to Hardt and Negri involves the direct production of subjectivity and social relations (M. Hardt and A. Negri, Empire (Cambridge, MA: Harvard University Press, 2000).) - reaffirmed and even reinvigorated the processes of psychologization.

${ }^{68}$ M. C. Lamia, "Making Psychology a Household Word-Just for Kids," Professional psychology, research and practice 37, no. 2 (2006): 114.

${ }^{69}$ Ibid., 115.

${ }^{70}$ Ibid., 116.
} 
is. Zimbardo's 'real of man' is paradigmatic to, for example, the authenticity trope in psychologization processes. ${ }^{71}$ We also see it in reality TV and psychotainment shows that supposedly lay bare the real, authentic psychological human condition. ${ }^{72}$ But the more sophisticated place of real 'man' today is of course the 'neurochemical self. ${ }^{73}$ Coming in brain-charts and gnome-patterns this new homunculus can be said to have taken the lead role in today's psychologization processes, of course only seemingly bypassing the paradoxical fact that the (post)modern subject is the enigmatic leftover of the process of objectivation.

The fact that the rebirth of psychology after the war had to come in two steps - Milgram and then Zimbardo - might appear as a repetition of the original double birth of psychology as postulated by the Belgian historian Jacques Claes. For Claes, psychology first emerged in the Renaissance where this new discipline had to reconnect 'man' with a receding world. ${ }^{74}$ In an increasingly secularized world, psychology came to replace religion as the mediator between 'man' and his world. Psychology's second birth comes with Gustav Theodor Fechner's psychophysics. ${ }^{75}$ Fechner regrounded psychology within the hard sciences and conceived of 'man' as a psychophysical being in order to try to reconcile 'man' with the modern, rapidly technologized world. The second birth is a repetition, but one that consolidates the first birth within the emerging dominant framework in society. Postwar psychology, in the same way, is characterized by a double birth. Milgram, in the passage from master discourse to the university discourse, regrounded psychology as a science that psychologizes its subject. Zimbardo reinforces this process of psychologization within the late-modern dominance of the university discourse.

If we contest the emancipatory character of Milgram's experiments, then we should expect to find nothing different in Zimbardo's experiment. If Milgram psychologized the past of the Nazi era, we can, perhaps, understand Zimbardo as having pre-empted forms of torture to come, creating, as it where, a rationale for so-called psychological torture. Phil Banyard already questioned the legitimacy of Zimbardo's taking part in the Abu Ghraib scandal debate, suggesting a direct route from Zimbardo's own experiment to Abu Ghraib. Banyard argued that, behind the scenes of the black sites, there were psychologists feeding the guards ideas on how to deal with the prisoners. ${ }^{76}$ This should lead us to doubt whether mainstream psychology can ever, as Dan Aalbers puts it, be part of

\footnotetext{
${ }^{71}$ E.g. K. McGowan, "Second Nature.."

${ }^{72} \mathrm{~J}$. De Vos, "On cerebral celebrity and reality TV. Subjectivity in times of brain-scans and psychotainment."

${ }^{73} \mathrm{~N}$. Rose, "Psychology as a Social Science."

${ }^{74}$ J. Claes, Psychologie, een dubbele geboorte. 1590 en 1850: bakens voor modern bewustzijn.: 31.

${ }^{75}$ Ibid.

${ }^{76}$ P. Banyard, "Tyranny and the tyrant. Zimbardo's 'The Lucifer Effect' reviewed," 495.
} 
the clean-up crew striving to stop the abuses in contexts where it has informed abuses as in Abu Ghraib and Guantanamo. ${ }^{77}$

77 D. Aalbers, "APA Approves Measure Banning Psychologists from Interrogations," Cageprisoners.com, http://www.cageprisoners.com/articles.php?id=26476. 